\title{
Theoretical foundations and principles of development of various forms of management in the agricultural sector of Russia in the new economic reality
}

\author{
Marina Kholodova ${ }^{1, *}$ \\ ${ }^{1}$ Federal Rostov Agricultural Research Centre (FSBSI FRARC), Institutskaya str., 1, p. Rassvet, \\ Aksay district, Rostov region, 346735, Russia
}

\begin{abstract}
The article examines and systematizes the basic principles of the development of various forms of management in the agricultural sector of Russia in the new economic reality. In this paper, special attention is paid to the principles of the development of integrated agricultural formations, the vector of which is aimed at the accelerated provision of food independence of the country and the implementation of an exportoriented strategy. In the framework of the present article, the above principles have been modified to reflect new economic reality and augmented the next group of principles of formation and development of various forms of management in the agricultural sector APK: mezhvedomstvennoi and complexity, the scientific justification for the introduction of technology, optimality and adequacy of the amount of state support, individual approach and differentiation of measures of state support, depending on the form of management and type of reproduction. It is proved that the principles of state regulation act in the conditions of the new economic reality as a set of objective economic laws, rules of conscious state support of socio-economic processes in the agro-industrial complex, which determine the directions of development of economic entities.
\end{abstract}

\section{Introduction}

The global trends of economic processes in the agro-industrial complex are characterized by the development of large integration formations based on the cooperation of production activities of various forms of management, stimulating the creation of powerful transnational corporations in the field of food.

The modern multi-layered economy of agriculture in Russia is a complex socioeconomic system and requires the formation of unified principles of managerial interaction, covering the entire set of production and economic relations and ties on a large scale.

Studies have shown that at present, significant transformational changes are observed in the country's agriculture, both related to the reform of property relations, the choice of

\footnotetext{
* Corresponding author:kholodovama@rambler.ru
} 
national priorities, the reorganization of economic entities, and the integration of the country into the global economic space, the struggle for leadership in the global agri-food market. These trends led to the emergence of new forms of economic interaction and forced a new perception of the principles of development of agricultural producers of various forms of management, traditional for the socialist economy [25]. A striking example of such a form of economic interaction in the agro-industrial complex is agricultural consumer cooperation, based on the principles of adequacy, adaptability, determinism and innovation $[1,2,3]$.

The need in the shortest possible time to solve the problem of food security, as well as to determine a new path is not a resource model of economic growth in Russia has led to the development of Agroholding structures should be based on the principles of agility, optimal size and concentration of production, consistency, hierarchy and allocation of key managers, and support from the state.

\section{Research Result}

Let us consider a detailed multidimensional description of the principles of the formation of large integrated structures in Russian agriculture during the implementation of national priorities. Thus, the principle of maneuverability and adaptability implies high flexibility and mobility of key participants of integration formations to dynamic changes in the macroeconomic environment and the transformation of natural factors of management in order to minimize their impact on production processes.

The principle of optimal size is aimed at creating a clear hierarchical management structure, in which the interests of all participating enterprises are coordinated and interconnected.

The principle of concentration of production and centralization of capital allows large agricultural formations to become a decisive force in the development of the domestic agricultural economy.

The principle of consistency considers integrated formation in the agricultural sector as a set of organizational and economic elements of management that have a single interconnected structure.

The principle of identifying the " key " link-provides that the role of the integrator enterprise can be played by a financially stable economy that has a strong production potential and is significantly ahead of other participants in the agricultural formation.

The essence of the principle of assistance and support from the state is that the authorities should promote the development of all participating enterprises, regardless of their size, financial, economic and material-technical components $[4,5,6]$.

Studies have shown that the adequacy of the institutional environment, represented by a set of universal theories, laws, rules, and norms of economic activity, determines the promising directions for the development of various forms of management in the agricultural sector. It should be noted that some of them, having an objective basis, can be applied in any socio-economic relations, while others, being the product of these relations, can self-destruct during the transformation of the directions of the state agrarian policy.

Thus, the basic principles of rational organization and development of various forms of management in agriculture in the conditions of market structural transformation, including: planning, specialization, complexity, optimality, continuous change( continuity), flow, uniformity, parallelism (Fig. 1), at certain stages of the development of the national economy, not only changed the vector of its orientation and methods of implementation, but also were supplemented with new provisions that reduce or, on the contrary, increase the degree of impact on the activities of economic entities of macro and micro-economic factors. 


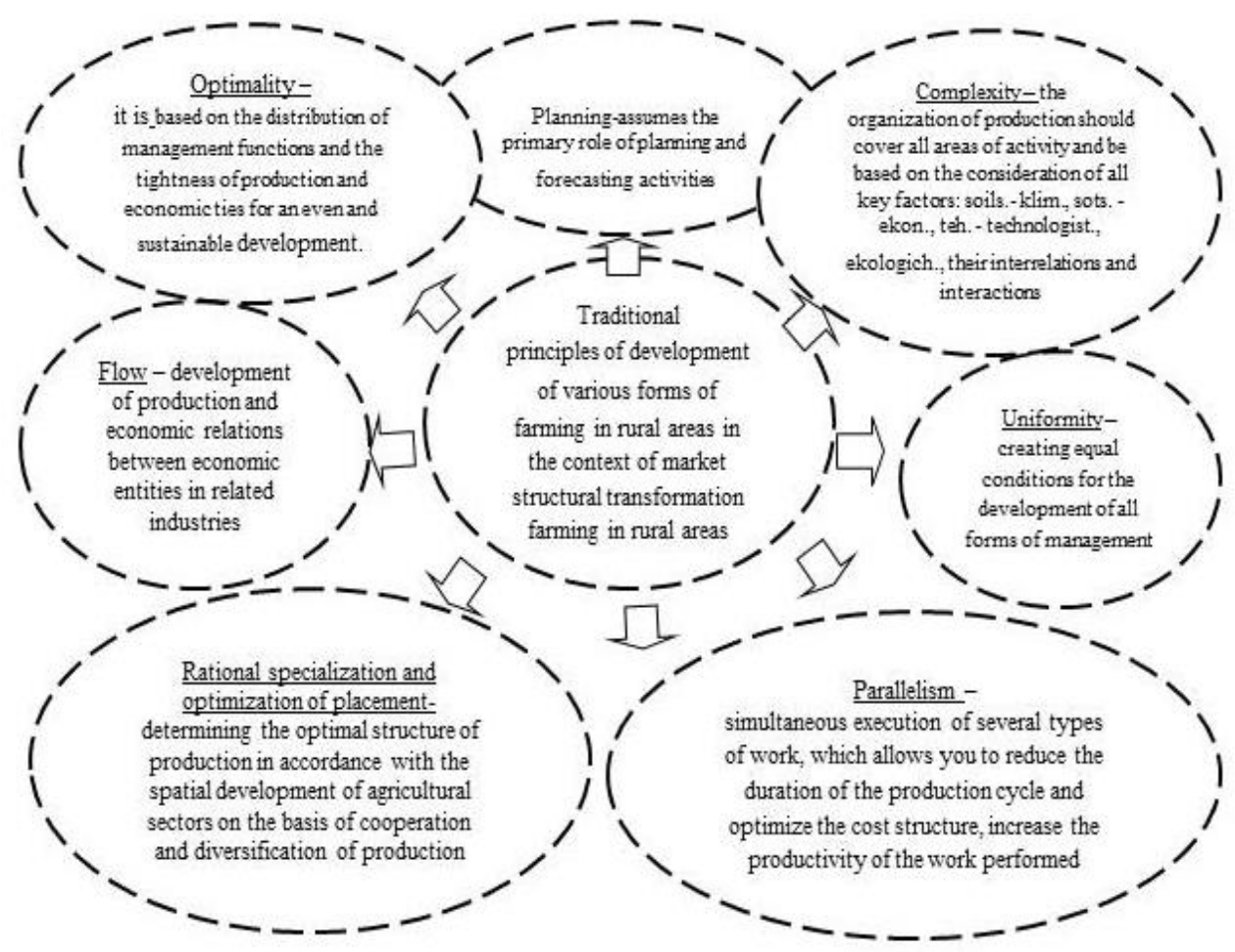

Fig. 1. Principles of development of various forms of farming in rural areas in the context of market structural transformation. Source: developed by the authors.

In particular, we were systematized the principles of the development of different forms of management in agricultural sector agriculture under the new economic reality (Fig.2).

In the successful development of various forms of management in the agricultural sector has a special role to the principle of economic feasibility, as it is the regulatory and management through increasing the efficiency of production of agricultural products based on the optimal combination of different types of farms in the form of ownership, size, technical equipment etc.

The formation of this methodological position is carried out through a system of production and economic relations, which give rise to the principle of an optimal combination of forms of ownership and forms of management, determining the optimal structure of the agricultural sector, represented by the ratio of dynamic proportions between large agricultural holding formations, small and medium-sized agribusiness, state unitary enterprises. The proportions may vary depending on time and regional specifics, taking into account its sectoral structure, the level of food self-sufficiency, the nature-exploiting nature, and the availability of labor resources $[7,8,9]$. 


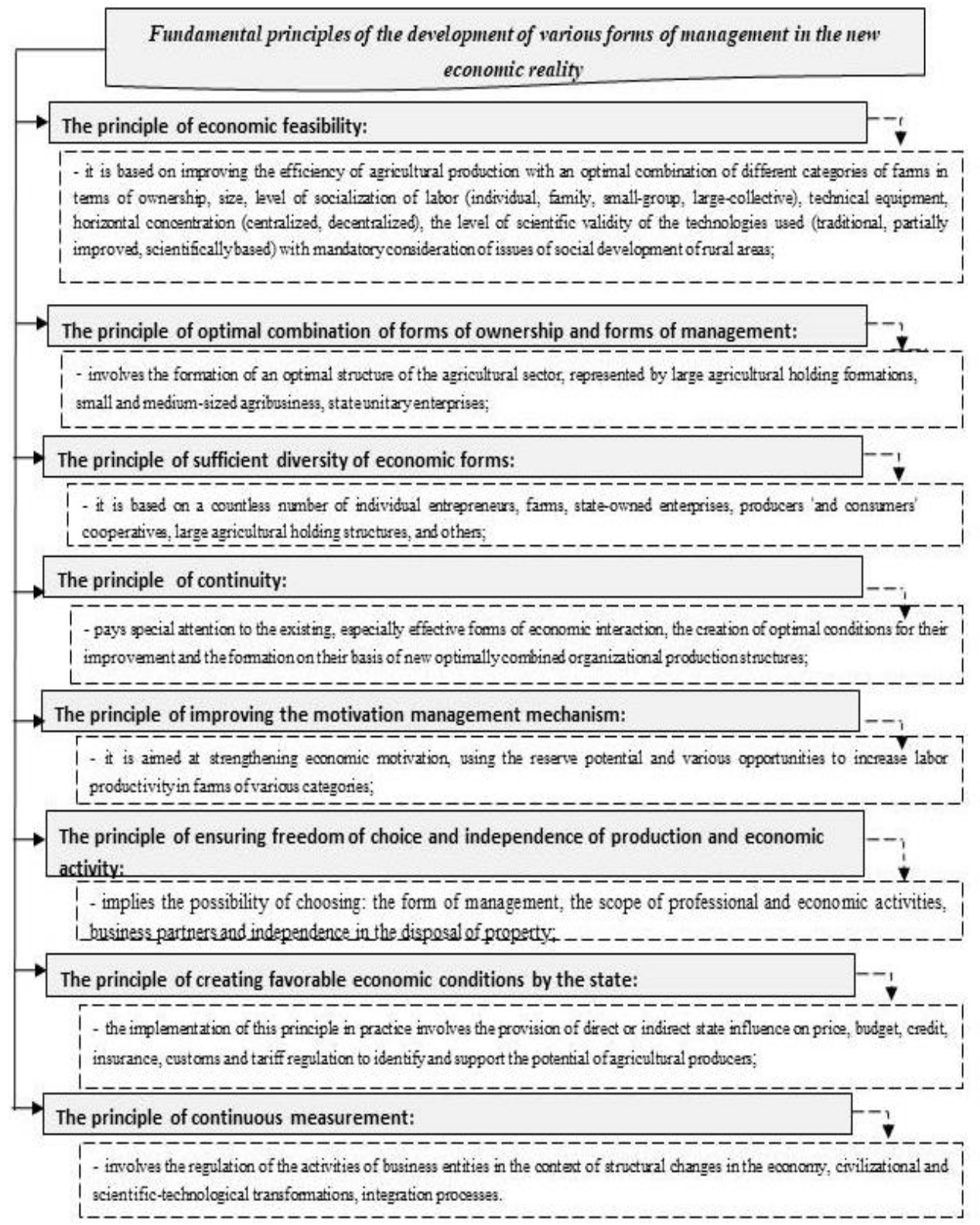

Fig. 2. The fundamental principles of the development of various forms of management in the new economic reality. Source: developed by the authors.

This principle is the key to the effective functioning of any relatively small economic system, which can be the branch of agriculture.

In the course of the study, based on foreign experience and domestic specifics of agricultural production, we found that the optimal structure of the agricultural economy should consist of 65-70 $\%$ of the small and medium-sized agribusiness sector, 20-25\% - large agricultural holding structures, $10-15 \%$ - the public sector. The presented agricultural structure is a target reference point and a guarantee of highly efficient agricultural production. In the context of the globalization of the world economy and integration into the world economic relations of the Russian Federation, the implementation of the principle of achieving an optimal combination of forms of ownership 
and forms of management is their sufficient diversity. At the same time, each of the forms of management occupies a certain position in the system of production and economic relations, complementing each other.

At the same time, modern methodological provisions should reflect the close relationship between the established forms of management and economic interaction, ensuring the improvement and formation of new optimally combined organizational production structures based on the principles of continuity in order to create favorable conditions for their successful functioning.

Improving the mechanism for managing the motivation of agricultural producers is a key principle of forming the structure of the agricultural economy. In this regard, in the emerging or already existing forms of management, special attention should be paid to strengthening their economic motivation, using the reserve potential and various opportunities to increase labor productivity. Special attention should be focused on improving labor relations in the system of functioning of all forms of management, internal financial policy, forms and methods of social protection and other aspects of the socioeconomic life of employees and their families.

In modern organizational and economic systems, such priority principles as ensuring freedom of choice for agricultural producers to carry out their production and economic activities in suitable forms of management and its independence, which follow from the principle of freedom of entrepreneurial activity, are important. The principle of continuous measurement implies the need for continuous regulation and modification of the directions of production and economic activity of business entities, taking into account the ongoing structural changes in the economy, civilizational and scientific-technological transformations, and integration processes.

From a methodological point of view, in the current economic conditions, the principle of creating favorable economic conditions for the development of agricultural producers of various forms of management is of great importance. The implementation of this principle in practice involves the provision of direct or indirect state influence on the price, budget, credit, insurance, customs and tariff regulation to identify and support potential farmers, large and medium-size farms and small, that is, the creation of equal opportunities on a par with freedom of choice forms of management.

The state's influence on the creation of favorable external economic conditions for farmers of various forms of management should, in turn, rely on the principles of state regulation of agricultural producers of different forms of management, the composition of which was determined on the basis of research and analysis conducted VNIIAEN Department of Regional economy [10, 11, 12] and in 2018 and 2019. in the framework of the "development of the concept of development of the diversity of forms of management in agriculture of the Russian Federation in the conditions of "new normality" and "to Develop organizational-economic mechanism of development of various forms of management in the agricultural sector of agriculture in the new economic reality."

In particular, the principles of state regulation that determine the sustainable functioning of agricultural producers should include (Fig. 3): 


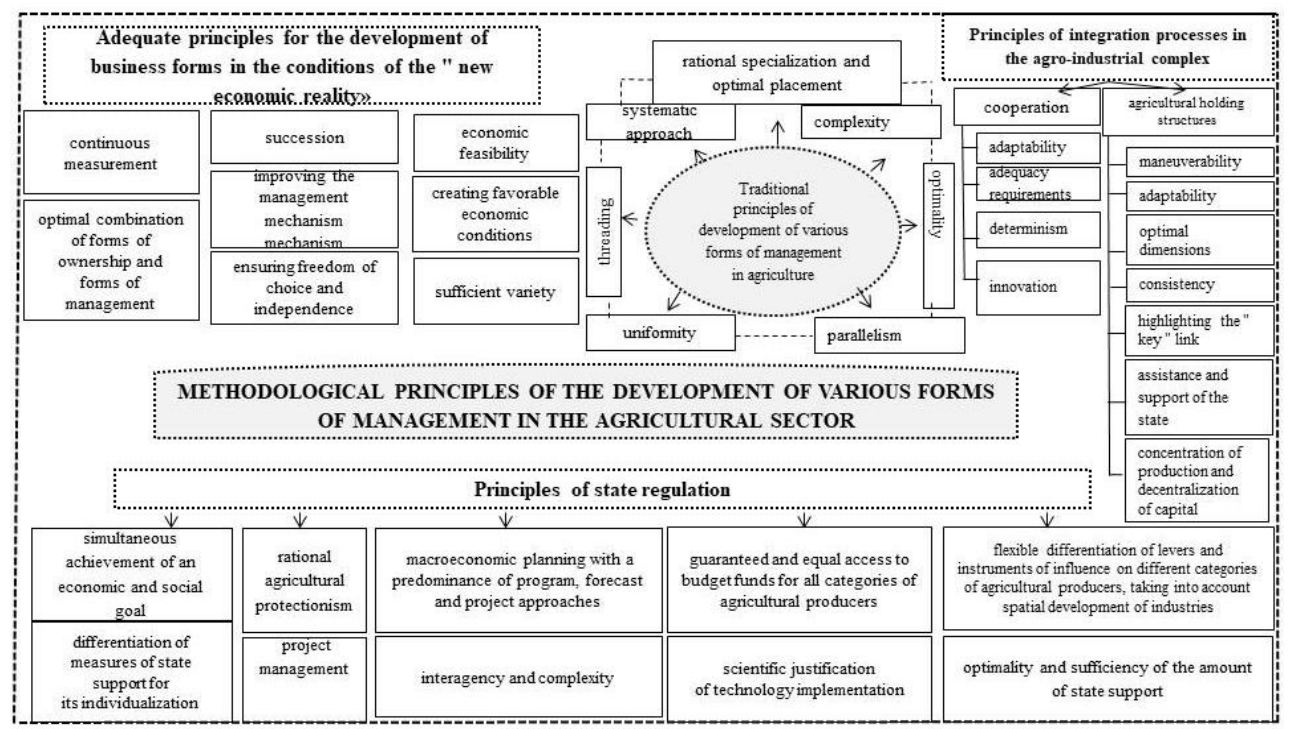

Fig. 3. Methodological principles of the development of various forms of management in the agricultural sector of the agro-industrial complex. Source: developed by the authors.

- simultaneous achievement of an economic and social goal,

- the principles of macroeconomic planning, assuming the dominance of its indicative forms with the predominance of program, forecast and project approaches,

- the principles of rational agricultural protectionism, which presuppose an optimal combination of domestic and foreign economic measures to protect domestic agricultural producers $[13,14]$,

- the principles of project management, which imply the distribution of direct payments (subsidies, subventions, subsidies) and indirect: diversified tax support, short-term and long-term concessional lending to small agribusiness and other preferences, legally enshrined in various national projects,

- guaranteed equal access to budget funds for all categories of commodity producers $[15,16]$

- the principle of flexible differentiation of levers and instruments of influence on different categories of agricultural producers, taking into account the spatial development of agricultural sectors $[17,18,19]$.

It should be noted that the stated principles may change over time, depending on the directions of the state agrarian policy.

Thus, the principles of state regulation appear in the conditions of the new economic reality as a set of objective economic laws, rules of conscious state support for socioeconomic processes in the agro-industrial complex, which determine the direction of development of economic entities.

Within the framework of the presented scientific development, the above principles were finalized taking into account the new economic reality and the set goal and supplemented with the following group of principles for the formation and development of various forms of management in the agricultural sector of the agro-industrial complex:

- scientific justification for the introduction of technologies-assumes that the provision of state support should take into account the objectivity of the choice of a particular technology of agricultural production in the conditions of a particular form of management, - the optimality and sufficiency of the amount of state support-means that direct subsidies to various forms of management should ensure their maximum efficiency at a small size, 
- differentiation of the instruments of state support and its individualization depending on the form of management and the type of reproduction. It is necessary to move from a unified and depersonalized state support to an individual approach that encourages the uniform development of all economic entities, bringing small and medium-sized agribusiness to the advanced level of production[20].

\section{Conclusion}

Thus, we identify and classify the principles of developing different forms of management in the agricultural sector APK categories defined in the research process for several years, reflecting the challenges of today's economic realities, with an emphasis on a direct influence of the state on the process.

\section{References}

1. V.N. Minaev, Scientific Herald YUIM 2, 74-81 (2018)

2. M.S. Anokhina, A.V. Golubev, O.N. Kondrasheva, Journal of Environmental Management and Tourism 10.1(33), 119-134 (2019).

3. N.G. Vozhdaeva, I.V. Volkov, V.A. Kozlov, A.V. Pavlov, Azimuth of scientific research: Economics and management 8.2(27), 103-108 (2019)

4. N.N. Lipatova, Intelligence. Innovation. Investment 1, 43-50 (2020) doi: 10.235198/2077-7175-2020-1-43.

5. O.A. Kholodov, Fundamental and applied research of the cooperative sector of the economy 1, 127-137 (2020)

6. A.A. Dibirov, O.A. Pogodina, O.V. Evolutionary, Russian electronic scientific journal 1 (35), 243-257 (2020)

7. A.F. Maximov, Economics, labor, and management in agriculture 6(39), 69-75 (2018)

8. N.N. Lipatova, Intelligence. Innovation. Investment 1, 43-50 (2020) doi: 10.235198/2077-7175-2020-1-43

9. M.N. Suray, Zh.N. Dibrova, O.A. Sagshina, B.L. Orlov, Food Processing: Techniques and Technology 48(1), 680-688 (2018) doi: 10.21603/2074-9414-2018-1-172-183

10. T. Yanina, Agroindustrial complex: economy and management 3, 44-50 (2017)

11. L.N. Usenko, Y.G. Chernysheva, V.A. Guzey, O.M. Todorova, A.M. Usenko, International journal of trade and global markets 2-3, 160-167 (2017) doi: 10.1504/ijtgm.2017.086074

12. M. Slozhenkina, I. Gorlov, M. Kholodova, O. Kholodov, O. Shakhbazova, D. Mosolova, AGRITECH-III-2020 IOP Conf. Series: Earth and Environmental Science 548 (2020) doi:10.1088/1755-1315/548/8/082037

13. A. Tkach, M. Radieva, V. Kolomiiets, Espacios 40(22), 223-228 (2019)

14. A.A. Maksaev, E.P. Bagryantseva, V.Yu. Dianova, N.V. Yatsevich, A.V. Tkach, Studies in Systems, Decision and Control (2021) doi: 10.1007/978-3-030-57831-2_40

15. P.I. Gochiyaeva, A.B. Urusova, Fundamental Research 5-1, 106-110 (2016)

16. I. Ushachev, N. Zhukov, V. Eremeev, Economics of agricultural and processing enterprises 10, 2-8 (2017)

17. S. Podgorskaya, A. Podvesovsky, R. Isaev, Control Sciences 5, 49-59 (2019) doi: http://doi.org/10.25728/pu.2019.5.5 
18. O. Isaeva, M. Kabanenko, A. Chistyakov, L. Dubrova, N. Filin, E3s Web of Conferences 175, 13004 (2020) doi: 10.1051/e3sconf/202017513022

19. V. Uzun, N. Shagaida, Z. Lerman, Land Use Policy 83, 475-487 (2019) doi: /10.1016/j.landusepol.2019.02.018

20. M.Y. Veselovsky, M.A. Izmailova, A.V. Bogoviz, S.V. Lobova, A.N. Alekseev, Quality - access to success 19(162), 60-66 (2018) 